\title{
Predictors of a good response to inhaled corticosteroids in obesity-associated asthma
}

\author{
S. Peerboom ${ }^{\text {a }}$, S. Graff ${ }^{a}$, L. Seidel ${ }^{b}$, V. Paulus ${ }^{a}$, M. Henket ${ }^{a}$, C. Sanchez ${ }^{a}$, F. Guissard ${ }^{a}$, \\ C. Moermans ${ }^{\mathrm{a}}$, R. Louis ${ }^{\mathrm{a}}$, F. Schleich ${ }^{\mathrm{a}, *}$ \\ ${ }^{a}$ Department of Pulmonary Medicine, CHU Sart-Tilman, Liege, $I^{3}$ GIGA Research Group, University of Liege, Belgium \\ ${ }^{\mathrm{b}}$ Medical Informatics and Biostatistics, University of Liege, Belgium
}

\section{A R T I C L E I N F O}

\section{Keywords:}

Obesity

Asthma

Phenotypes

Inflammation

Treatment response

Predictor

\begin{abstract}
A B S T R A C T
Introduction: Asthma in obese subjects is poorly understood. According to GINA guidelines, pulmonologists increase ICS in case of poor asthma control but lung volume restriction may also worsen respiratory symptoms in obese asthmatics leading to overtreatment in this subpopulation.

Methods: We conducted a retrospective study on 1217 asthmatics recruited from University Hospital of Liege. 92 patients with a BMI $\geq 30$ came at least two times at the asthma clinic (mean interval: 335 days). In this obese population, we identified predictors of good (decrease in ACQ $\geq 0.5$ ) versus poor response (rise in ACQ $\geq 0.5$ ) to ICS step-up therapy.

Results: Obese asthmatics had a poorer asthma control and quality of life as compared to non-obese and exhibited reduced FVC, higher levels of blood leucocytes and markers of systemic inflammation. The proportion of asthma inflammatory phenotypes was similar to that observed in a general population of asthmatics. Among uncontrolled obese asthmatics receiving ICS step-up therapy, 53\% improved their asthma control while $31 \%$ had a worsening of their asthma. Uncontrolled obese asthmatics showing a good response to increase in ICS had higher ACQ, lower CRP levels, higher sputum eosinophil counts and higher FeNO levels at visit 1. Uncontrolled obese asthmatics that worsened after increasing the dose of ICS had lower FVC, lower sputum eosinophil counts and higher sputum neutrophil counts.

Conclusion: We observed poorer asthma control in obese asthmatics despite similar bronchial inflammation. Managing obese asthmatics according to ACQ alone seems to underestimate asthma control and the contribution of restriction to dyspnea. Increasing the dose of ICS in the absence of sputum eosinophilic inflammation or in the presence of restriction or bronchial neutrophilia led to poorer asthma control. In those patients, management of obesity should be the first choice.
\end{abstract}

\section{Introduction}

Asthma in obese subjects is poorly understood. Asthma and obesity are both common diseases in developed countries. More than 600 million people are obese worldwide. According to the data from our asthma clinic, $20 \%$ of our asthmatics are obese and this rate increases up to $25 \%$ in severe asthmatics included in the Belgian Severe Asthma Registry [1]. The majority of studies evaluating the link between obesity and the prevalence and incidence of asthma in adults or exploring the relationship between obesity and asthma severity concluded that obesity was associated with a significant increase in the annual risk of a new diagnosis of asthma [2-4]. The association of obesity with severe asthma remains controversial. It has been suggested that obesity was a consequence of asthma treatment but it is now clear that obesity often precedes asthma [5]. Mechanical [6], inflammatory and genetic factors [7] contribute to the development of asthma in obese patients [8].

The aim of asthma management is to obtain asthma control and to reduce the risk of exacerbation. The GINA guidelines [9] recommend to step-up or step-down the ICS dose according to asthma symptoms questionnaires. However, obese patients do not respond as well as normal-weight individuals to inhaled corticosteroids or inhaled corticosteroid/long-acting bronchodilator combination medications $[10,11]$ Obesity indeed causes physiologic impairment in lung function due to the mechanical effect of central body fat distribution [12] and symptoms related to lung volume restriction will not improve with a step-up of asthma therapy. This could lead to obese asthma overtreatment. In

\footnotetext{
* Corresponding author at: SCHLEICH Florence, CHU Sart-Tilman B35, 4000 Liege, Belgium.

E-mail address: fschleich@chuliege.be (F. Schleich).
} 
the area of personalized medicine, the obese-asthma phenotype remains controversial [13-16], some of the clusters analysis suggesting that this obese asthma phenotype is not a uniform group and identifying two major subgroups according to $\mathrm{TH}_{2}$ inflammation and the age of onset.

The aim of this study was to describe the characteristics of obese as compared to normal-weight asthmatics and to identify predictors of poor or good responders to ICS step-up therapy in this particular asthmatic population.

\section{Material and methods}

\subsection{Subject characteristics}

We conducted a retrospective study on a series of 1217 patients with asthma recruited from the University Asthma Clinic of Liege between October 2005 and June 2017. The patients came from routine practice to University Hospital and were recruited by two clinicians involved in asthma. Entry criteria were any patients with asthma aged 18yrs or more who accepted to undergo detailed investigation at the Asthma Clinic. The visits were not parts of an asthma trial. All the patients that had a successful sputum induction were included in the study. Their demographic and functional characteristics are summarised in Tables 1 and 2 .

Asthma was diagnosed based on the presence of chronic respiratory symptoms such as cough, breathlessness or dyspnoea together with the demonstration of airflow variability. The latter was defined by airway hyper-responsiveness shown by one or more of the following: increase in Forced Expiratory Volume in $1 \mathrm{~s}\left(\mathrm{FEV}_{1}\right)$ of $>12 \%$ and $200 \mathrm{ml}$ following inhalation of $400 \mu \mathrm{g}$ salbutamol (VENTOLIN ${ }^{\mathrm{TM}}$, GSK Belgium) or inhaled concentration of methacholine (Methapharm inc., Brandford, Ontario, Canada) provoking a $20 \%$ fall in $\mathrm{FEV}_{1}$ of $<16 \mathrm{mg} / \mathrm{ml}$. Methacholine challenge was performed according to a standardised methodology as previously described [17]. Subjects were characterised as atopic if they had at least one positive specific $\operatorname{IgE}(>0.35 \mathrm{kU} / \mathrm{l}$; Phadia) for at least one common aeroallergen (cat, dog, house dust mites, grass pollen, tree pollen and a mixture of moulds). Patients with a smoking history of more than 20 pack-years were excluded. Subjects with BMI under 30 were defined as non-obese and subjects with BMI over 30 as obese asthmatics.

\subsection{Study design}

Patients underwent FeNO measurement at a flow rate of $50 \mathrm{ml} / \mathrm{s}$ according to the ERS/ATS recommendations (NIOX, Aerocrine, Sweden). FeNO was first measured and followed by spirometry with bronchodilation, sputum induction and blood sampling. All tests were performed on the same day.

Quality of life was assessed using the self-administered Asthma Quality of Life Questionnaire (AQLQ [18]) and asthma control by the Juniper Asthma Control Questionnaire (ACQ [19]). Sputum was induced and processed as previously reported [20]. Cell count were estimated on samples centrifuged (Cytospin) and stained with Diff Quick after counting 500 cells (Dade, Brussels, Belgium).

\subsection{Statistical analyses}

The results were expressed as means \pm standard deviation (SD) for continuous variables or as medians and interquartile ranges (IQR) for skewed distributions. For categorical variables, the number of observations and percentages were given in each category. Comparisons between different subgroups were performed with ANOVA test or a Kruskal-Wallis test. The Spearman correlation coefficient was used to measure the association between clinical parameters. Univariate linear regression models were used to assess the relationship between ACQ, AQLQ and BMI with a set of covariates. Some parameters were logtransformed to normalize their distribution. ICS was divided in three groups according to tertiles $(<400, \geq 400-1000$, $\geq 1000)$. A multivariate analysis with stepwise selection was done including all independent variables. The results were considered to be significant at the $5 \%$ critical level ( $\mathrm{p}<0.05)$. Calculations were done using SAS Version 9.1 (SAS Institute, Cary, North Carolina, USA).

Table 1

Demographic and clinical characteristics of asthmatics classified according to BMI.

\begin{tabular}{|c|c|c|c|c|}
\hline & Overall & $\mathrm{BMI}<30$ & BMI 30-35 & $\mathrm{BMI} \geq 35$ \\
\hline $\mathrm{N}$ & 1217 & $969(80 \%)$ & $177(14 \%)$ & $71(6 \%)$ \\
\hline Sex $(F)$ & $717(59 \%)$ & $565(58 \%)$ & $103(58 \%)$ & $49(69 \%)$ \\
\hline Age, years & $49(35-60) * * * *$ & $47(33-60)$ & 54 (43-64) †十 & $50(37-62)$ \\
\hline Smoking history (S/ES/NS), \% & $21 / 26 / 53$ & $22 / 26 / 52$ & $19 / 31 / 50$ & $17 / 23 / 60$ \\
\hline Packs-years & $0(0-10)$ & $0(0-8)$ & $0(0-17)$ & $0(0-7)$ \\
\hline Atopy (Y) & $706(58 \%)$ & $610(63 \%)$ & $97(55 \%)$ & $36(51 \%)$ \\
\hline Exacerbation (n/yr) & 0.66 & 0.68 & 0.48 & 0.67 \\
\hline ICS & $766(63 \%)$ & $594(61 \%)$ & $114(64 \%)$ & $55(77 \%) \infty$ \\
\hline Beclomethasone equivalents & $400(0-1000) * *$ & $400(0-1000)$ & $800(0-1000)$ & $800(200-2000) \infty \infty$ \\
\hline OCS & $87(7 \%)$ & $65(7 \%)$ & $14(8 \%)$ & $8(11 \%)$ \\
\hline LABA & $711(58 \%)$ & $541(56 \%)$ & $116(66 \%) \dagger$ & $54(76 \%) \infty \infty$ \\
\hline LTRA & $292(24 \%)$ & $222(23 \%)$ & $44(25 \%)$ & $26(37 \%) \infty$ \\
\hline Anticholinergics & $352(29 \%)$ & $267(28 \%)$ & $57(32 \%)$ & $28(39 \%)$ \\
\hline $\mathrm{FEV}_{1} \%$ & $84 \pm 21$ & $84 \pm 21$ & $83 \pm 22$ & $80 \pm 21$ \\
\hline FVC\% & $95 \pm 18 * *$ & $96 \pm 18$ & $92 \pm 21$ & $89 \pm 19 \infty \infty$ \\
\hline $\mathrm{FEV}_{1} / \mathrm{FVC}$ & $73 \pm 11 * *$ & $73 \pm 11$ & $75 \pm 11$ & $76 \pm 10 \infty$ \\
\hline ACQ & $2,01 \pm 1,23 * * * *$ & $1,93 \pm 1,22$ & $2,28 \pm 1,21 \dagger$ & $2,51 \pm 1,21 \infty \infty \infty$ \\
\hline ACT & $15 \pm 5 * * * *$ & $15 \pm 5$ & $14 \pm 5 \dagger$ & $12 \pm 5 \infty \infty \infty$ \\
\hline AQLQ & $4,52 \pm 1,36 * * * *$ & $4,61 \pm 1,34$ & $4,25 \pm 1,31 \dagger$ & $3,84 \pm 1,48 \infty \infty \infty \infty$ \\
\hline Age of onset & $30(11-50)$ & $31(12-49)$ & $32(12-84)$ & $28(10-51)$ \\
\hline Early/late onset $(<12 />40 \mathrm{yr})$ & $258 / 391$ & $204 / 310$ & $40 / 58$ & $14 / 23$ \\
\hline
\end{tabular}

$\dagger$ compares BMI 30-35 to BMI $<30$ group; $\infty$ compares BMI $\geq 35$ to BMI $<30$ groups; ${ }^{\mathrm{x}}$ compares BMI $\geq 35$ to BMI $30-35$ groups. $* / \uparrow / \infty /{ }^{\mathrm{x}}: \mathrm{p}<0,05 .{ }^{* *} / \uparrow \uparrow /$

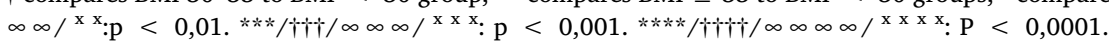

BMI: body mass index. F: female. M: male. S: current smoker. ES: ex-smoker. NS: non-smoker. Y: yes. N/yr: number per year. ICS: inhaled corticosteroids. OCS: oral corticosteroids. LABA: Long acting Beta 2 Agonists. LTRA: leukotriens receptor antagonists. $\mathrm{FEV}_{1}$ : forced expiratory volume in one second. FVC: forced vital capacity. ACQ: asthma control questionnaire. ACT: asthma control test. AQLQ: asthma quality of life questionnaire. 
Table 2

Inflammatory characteristics of asthmatics classified according to BMI.

\begin{tabular}{|c|c|c|c|c|}
\hline & Overall & BMI $<30$ & BMI 30-35 & $\mathrm{BMI} \geq 35$ \\
\hline Blood leucocytes, $10^{6} / \mathrm{mm}^{3}$ & $7,5(6,2-9,1) * * *$ & $7,3(6,1-8,9)$ & $7,8(6,7-9,4) \dagger$ & $8,2(6,8-9,7) \infty$ \\
\hline Blood neutrophils, $10^{3} / \mathrm{mm}^{3}$ & $4059(3156-5392) * *$ & $3970(3061-5325)$ & $4237(3465-5607)$ & $4482(3685-5824)$ \\
\hline Blood lymphocytes, $10^{3} / \mathrm{mm}^{3}$ & $2328(1869-2848) * * * *$ & $2270(1850-2771)$ & 2558 (2035-3165) † & $2528(2002-3212) \infty$ \\
\hline Blood eosinophils, $10^{3} / \mathrm{mm}^{3}$ & $190(110-333)$ & $191(110-335)$ & $181(109-320)$ & $184(109-350)$ \\
\hline Blood monocytes, $10^{3} / \mathrm{mm}^{3}$ & $511(397-668) * *$ & $500(388-657)$ & $514(424-672)$ & $563(465-725) \infty$ \\
\hline Blood basophils, $10^{3} / \mathrm{mm}^{3}$ & $36(24-53)$ & $36(23-53)$ & $37(27-57)$ & $36(23-54)$ \\
\hline Blood neutrophils, \% & $56(49-62)$ & $56(49-62)$ & $56(50-62)$ & $57(48-64)$ \\
\hline Blood lymphocytes, \% & $32(26-38)$ & $32(26-38)$ & $33(27-39)$ & $31(24-39)$ \\
\hline Blood eosinophils, \% & $2,6(1,5-4,3)$ & $2,7(1,5-4,5)$ & $2,4(1,6-4)$ & $2,6(1-4)$ \\
\hline Blood monocytes, \% & $6,9(5,4-8,5)$ & $6,9(5,4-8,6)$ & $6,7(5,4-8,4)$ & $7,2(5,7-8,8)$ \\
\hline Blood basophils, \% & $0,5(0,3-0,7)$ & $0,5(0,3-0,7)$ & $0,5(0,3-0,7)$ & $0,4(0,3-0,6)$ \\
\hline $\mathrm{CRP}, \mathrm{mg} / \mathrm{L}$ & $2,4(1-6) * * * *$ & $2(0,9-6)$ & $3,3(2-6)+1 \dagger$ & $4,4(2.1-9,4) \infty \infty \infty$ \\
\hline Fibrinogen, g/L & $3,2(2,8-3,7) * * * *$ & $3,2(2,7-3,6)$ & $3,5(2,9-3,9) \dagger$ & $3,7(3,2-4,2) \infty \infty \infty \infty$ \\
\hline IgE, kU/L & $120(39-335)$ & $123(40-349)$ & $118(41-302)$ & $84(34-269)$ \\
\hline Total cell count $\left(10^{6} / \mathrm{g}\right)$ & $1042(311-3027)$ & $1150(241-3658)$ & $1025(188-2925)$ & $1231(481-3606)$ \\
\hline IS eosinophils, $10^{3} / \mathrm{mm}^{3}$ & $21(0,5-173)$ & $21(0-176)$ & $20(1,9-138)$ & $25(0,5-192)$ \\
\hline IS neutrophils, $10^{3} / \mathrm{mm}^{3}$ & $474(160-1556)$ & $460(156-1482)$ & 548 (195-1849) & $714(198-2295) \infty$ \\
\hline IS lymphocytes, $10^{3} / \mathrm{mm}^{3}$ & $14,6(3,1-45,4)$ & $13,8(2,9-43,9)$ & $16,4(3-46,8)$ & $19,7(7,7-57,7)$ \\
\hline IS macrophages, $10^{3} / \mathrm{mm}^{3}$ & $262(111-640)$ & $258(106-643)$ & $257(112-604)$ & $345(159-802)$ \\
\hline IS eosinophils, $\%$ & $1,8(0,2-10,8)$ & $1,8(0,2-11)$ & $1,6(0,3-9,4)$ & $1,8(0,2-10,8)$ \\
\hline IS neutrophils, \% & $51,4(27,4-75,3)$ & $51(26,6-76)$ & $53,5(32,9-72,4)$ & $51,5(27,6-75,2)$ \\
\hline IS lymphocytes, \% & $1,4(0,5-2,7)$ & $1,2(0,4-2,8)$ & $1,6(0,5-2,6)$ & $1,6(0,7-2,6)$ \\
\hline IS macrophages, $\%$ & $23,8(11,1-44,3)$ & $23,8(10,6-45,6)$ & $23(12,2-39,9)$ & $26,4(13-45)$ \\
\hline FeNO, ppb & $24(14-49) * *$ & $25(14-52)$ & $20(12-42) \dagger$ & $22(12-35)$ \\
\hline
\end{tabular}

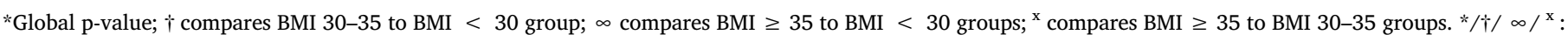

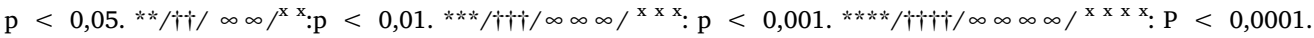

CRP: C reactive protein. IgE: immunoglobulin E. IS: induced sputum. FeNO: fractional exhaled nitric oxide. Ppb: part per billion.

\section{Results}

\subsection{Baseline characteristics}

Complete assessment was obtained in 1217 subjects with physiciandiagnosed asthma. $20 \%$ of our general asthmatic population was obese and $6 \%$ had a BMI $\geq 35$. Female was the predominant gender and mean age of our asthmatics was 49 years old with obese patients tending to be older (Table 1). $21 \%$ were current smokers while $26 \%$ were ex-smokers. Atopy did not differ according to BMI. Obese asthmatics received higher doses of ICS and more frequently LABA and anti-leukotrienes than non-obese. Overweight patients had poorer asthma control and quality of life. $72 \%$ of our obese asthmatic population had uncontrolled asthma. When looking more in depth at the ACQ questionnaire, it appeared that obese patients had significantly more morning symptoms, activity limitation, breathlessness and short-acting bronchodilator use than non-obese $(\mathrm{p}<0.05)$. They did not report more frequent nocturnal awakening or wheezing. Asthmatics with a BMI $\geq 30$ had similar FEV $_{1}$ values but reduced FVC (Table 1). Early onset of asthma was observed in one fifth of asthmatics while one third of the cohort had onset of disease after the age of 40 years old and this was similar within the different BMI subgroups.

Absolute value of blood leucocytes, including neutrophils, lymphocytes and monocytes were correlated with BMI with obese patients showing the highest levels (Table 2). CRP and Fibrinogen levels also increased with BMI. Successful sputum was obtained in $83 \%$ of the asthmatic population. The proportion of airway inflammatory phenotypes was similar in different weight subgroups (Fig. 1) but we found a significant increase in absolute sputum neutrophil counts in obese patients. Obese did not exhibit higher rate of exacerbations.

\subsection{Independent factors of poor asthma control and quality of life}

We conducted a multiple regression analysis in the general population of asthmatics to highlight independent predictors of asthma control (Table 3). Higher BMI, tobacco smoking, sputum eosinophil counts and high ICS dose were predictors of poorer asthma control

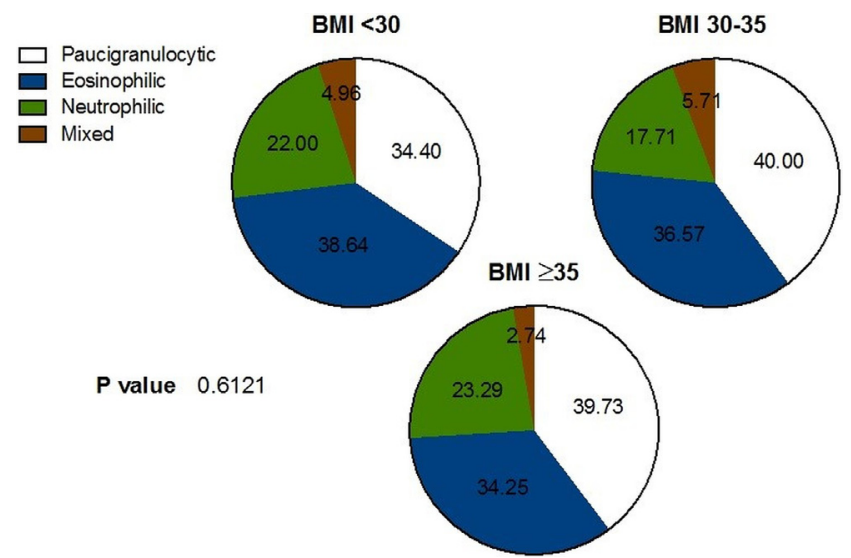

Fig. 1. Proportions of airway inflammatory phenotypes in asthmatics classified according to BMI.

while higher $\mathrm{FEV}_{1}$ values were associated with better asthma control $\left(\mathrm{r}^{2}=0.40, \mathrm{p}<0.0001\right)$. As for quality of life, multiple logistic regression analysis showed that male gender and higher FVC were independent predictors of better asthma quality of life while higher BMI and high doses ICS were associated with poorer AQLQ $\left(r^{2}: 0.23\right.$, $\mathrm{p}<0.0001)$.

\subsection{Effect of ICS in obese asthmatics}

Among the 146 uncontrolled asthmatics with normal weight that were prescribed an ICS step-up therapy, 88 patients $(60 \%)$ had an improvement of their asthma control at the following visit (decrease in ACQ $\geq 0.5)$ while 33 patients $(23 \%)$ had a worsening of their asthma (increase $\geq 0.5$ in ACQ score, Table 4). In the obese asthma population where ICS step-up therapy was prescribed due to poor asthma control ( $\mathrm{n}=57$ ), 29 asthmatics (53\%) improved their asthma control while 17 patients (31\%) had a worsening of their asthma symptoms (Table 4). The rate of responders did not significantly differ between obese and normal-weight asthmatics ( $\mathrm{p}>0.05)$. 
Table 3

Univariate and multivariate linear regression models to assess the relationship between Asthma control questionnaire (ACQ) and a set of covariates.

\begin{tabular}{|c|c|c|c|c|}
\hline \multirow[t]{2}{*}{ ACQ } & \multicolumn{2}{|l|}{ UNIVARIATE } & \multicolumn{2}{|c|}{ MULTIVARIABLE With stepwise selection } \\
\hline & Univariate Estimate (SE) & P-value & Estimate (SE) & P-value \\
\hline Tobacco Current Ex-smokers & $\begin{array}{l}0.57(0.090) \\
0.16(0.083)\end{array}$ & $<0.0001$ & $0.56(0.085)$ & $<0.0001$ \\
\hline BMI & $0.036(0.0071)$ & $<0.0001$ & $0.027(0.0071)$ & 0.0002 \\
\hline $\mathrm{FEV}_{1}$ & $-0.033(0.0014)$ & $<0.0001$ & -0.029 & $<0.0001$ \\
\hline FVC & $-0.033(0.0019)$ & $<0.0001$ & & \\
\hline $\mathrm{FEV}_{1} / \mathrm{FVC}$ & $-0.036(0.003)$ & $<0.0001$ & & \\
\hline ICS & & $<0.0001$ & & \\
\hline $400-1000$ & $0.40(0.084)$ & & $0.40(0.086)$ & $<0.0001$ \\
\hline$>1000$ & $0.91(0.079)$ & & $0.75(0.084)$ & $<0.0001$ \\
\hline Ln Leucocytes & $1.10(0.12)$ & $<0.0001$ & & \\
\hline Ln Lympho \% & $-0.69(0.11)$ & $<0.0001$ & & \\
\hline Ln Blood Eosinophils $(/ \mu \mathrm{L})$ & $0.18(0.041)$ & $<0.0001$ & & \\
\hline Ln Blood Neutrophils $(/ \mu \mathrm{L})$ & $0.73(0.085)$ & $<0.0001$ & & \\
\hline Ln Basophils $(/ \mu \mathrm{L})$ & $0.28(0.059)$ & $<0.0001$ & & \\
\hline Ln Fibrinogen & $0.35(0.18)$ & 0.046 & & \\
\hline Ln CRP & $0.17(0.034)$ & $<0.0001$ & & \\
\hline Ln Sputum Macrophages & $-0.23(0.035)$ & $<0.0001$ & & \\
\hline Ln Sputum Eosinophils & $0.13(0.023)$ & $<0.0001$ & & \\
\hline Ln Sputum Lympho, AV & $0.087(0.025)$ & 0.0004 & & \\
\hline Ln Sputum Neutrophils, AV & $0.090(0.02)$ & $<0.0001$ & & \\
\hline Ln Sputum Eosinophils, AV & $0.12(0.018)$ & $<0.0001$ & 0.095 & $<0.0001$ \\
\hline
\end{tabular}

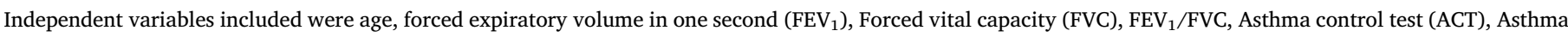

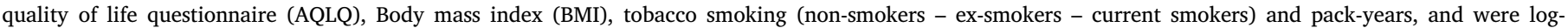

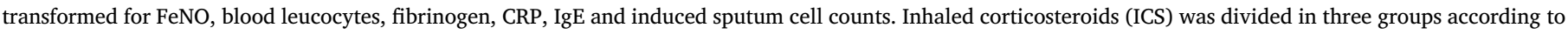

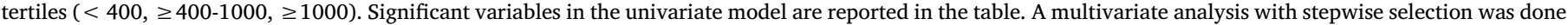
including all significant variables from the univariate model.

Uncontrolled obese asthmatics showing a good response to increase in ICS dose had poorer baseline ACQ (3.27 \pm 1.22 vs $2.24 \pm 1.11$, $\mathrm{p}<0.01)$, lower CRP levels (2.9 (0.9-5.2) vs 5 (3.2-8.8), $\mathrm{p}=0.04)$, higher sputum eosinophil counts either taken in percentage $(23.6 \%$ $(3.1-50)$ vs $6.2 \%(0.6-15), \mathrm{p}=0.01)$ or in absolute value $(393$ (35-1170) vs $72(2-274), \mathrm{p}=0,02)$ and higher FENO levels (48 $(20-74)$ vs 18 (12-43), $p=0.01)$. Uncontrolled obese asthmatics who worsened their asthma after increasing the dose of ICS had lower FVC $(78 \% \pm 19 \%$ vs $91 \% \pm 17 \%, \mathrm{p}=0.04)$, lower sputum eosinophil counts $(1.4 \%(0.6-9.8)$ vs $11 \%(1.8-29), \mathrm{p}=0.03)$ and higher sputum neutrophil counts $(73.4 \%$ (58-90) vs $43.4 \%$ (16-71), p = 0.04). After exclusion of current smokers, we found exactly the same characteristics of good and poor response to ICS. We did not find any differences in treatment response when looking at the age of onset.

\section{Discussion}

Obese asthmatics represent $20 \%$ of our asthmatic population. Obesity is associated with poor asthma control and quality of life and obese asthmatics exhibit signs of systemic inflammation.

We found that obese asthmatics have the same predictors of response to ICS than non-obese. The "obesity-associated asthma" phenotype includes a subgroup of patients with eosinophilic inflammation who will show a good response to ICS and another subgroup who is characterized by low FVC and neutrophilic inflammation who may even deteriorate with the increase in ICS dose.

In a general population of asthmatics, our data report that $20 \%$ are obese. Ford et al [21] found that $27.3 \%$ out of 13,953 asthmatics had a BMI $>30$. Female was the predominant gender in our study. As previous studies, we found the same proportion of atopic patients and similar $\mathrm{FEV}_{1}$ and $\mathrm{FEV}_{1} / \mathrm{FVC}$ in obese versus normal weight asthmatics $[22,23]$. Obese asthmatics had poorer asthma control and quality of life than those with normal weight. Only a low proportion of obese asthmatics reach asthma control with classic asthma therapy in our study which is in line with previous reports $[10,11]$. Our obese asthmatic population received higher doses of ICS, SABA and more frequently anti-leukotrienes and LABA than their non-obese counterpart. FVC was decreased in obese as compared to lean patients. This finding was already found by Holguin et al [23]. Alteration of thoracic mechanics may indeed contribute to greater symptom burden and poorer asthma control. As a consequence, respiratory physicians are tented to increase the dose of ICS according to GINA guidelines. However, thoracic and pulmonary compliance in those patients may be reduced due to thoracic compression by abdominal obesity. Obesity indeed reduces the downward movement of the diaphragm and change chest wall properties. These changes in the balance of forces that normally act on the lung increase the stiffness of the respiratory system [24] and reduce operating lung volumes, contributing to dyspnea [25]. A step-up in ICS dose in the absence of type 2 inflammation won't improve [26-28] and may even worsen asthma control due to side-effects.

In obese asthmatics, poor diet quality, physical inactivity and consequent excess of adipose tissue independently activates inflammatory pathways [29]. We found higher levels of blood leucocytes, CRP and fibrinogen and increased numbers of sputum neutrophils in our obese

Table 4

Proportion of good and poor responders to an ICS step-up therapy in uncontrolled asthma classified according to BMI.

\begin{tabular}{llr}
\hline & ACQ $\geq 1,5$, BMI $<30$ & ACQ $\geq 1,5$, BMI $\geq 30$ \\
\hline ICS step-up received (Y,\%) & $146(26 \%)$ & $57(32 \%)$ \\
Good responders & $88(60 \%)$ & $29(53 \%)$ \\
Poor responders & $33(23 \%)$ & $17(31 \%)$ \\
\end{tabular}

ACQ: asthma control questionnaire. BMI: body mass index. ICS: inhaled corticosteroids. 
asthmatic population. It was previously found that obesity is associated with systemic inflammation such as blood neutrophilia, elevated CRP and leptin levels [30]. Obesity is regarded as a low-grade chronic proinflammatory state that affects the cellular and molecular signaling pathways of the immune system. The total leukocyte count correlates with the degree of obesity and CRP and fibrinogen have been found to be elevated in obese asthmatics in a previous report [31]. We found higher sputum neutrophil counts in the obese subpopulation. It has been suggested that late-onset obese women have an increase in sputum neutrophils [32] and that fatty acids should activate the immune system by activation of toll-like receptors on epithelial cells conducing in nuclear translocation of $\mathrm{NFK} \beta$ and to the production of pro-inflammatory cytokines (TNF $\alpha$, IL-6 and IL-1) inducing neutrophilic inflammation [33]. We also know that exhaled air 8-isoprostane level, reflecting oxidative stress, is increased in obese asthmatics [8,34]. Scott et al. [33] have also shown that sputum neutrophils were associated with total plasma saturated fatty acids and negatively with mono-unsaturated fatty acids in men. Periyalil et al also found higher percentages of sputum neutrophils in obese versus lean asthmatics [35]. Other studies did however not find any significant increase in sputum neutrophils $[36,37]$. Baseline FENO values were similar to previously reported $[22,23,38]$. As other studies [39], we found that FENO was not correlated to BMI. In a previous study, we did not find any association between BMI and inflammatory phenotypes [40].

We looked at the predictors of a good or a poor response to ICS stepup therapy in obese uncontrolled asthmatics. Obese asthmatics who did not exhibit signs of eosinophilic inflammation but increased sputum neutrophils and low FVC were not improved by increasing the dose of ICS. The role of mechanical effects on the lungs in this subpopulation is more important and this may increase symptoms directly. This highlights the need to accurately define the contribution of obesity, as comorbidity, to the expression of asthma symptoms in patients on an individual basis. Cluster analyses and clinical observation have shown that obese asthmatics are not a uniform group. Several cluster analyses have identified two major groups of obese asthmatics that are categorized by age of onset of asthma [16] as well as $\mathrm{TH}_{2}$ inflammation [14].

Our results suggest that phenotyping obese asthma in different inflammatory phenotypes seems as important as in non-obese asthmatics to predict the response to therapy. Previous studies have shown that weight loss resulted in a dramatic improvement in asthma control by improving lung mechanics [41] and systemic inflammation [38] but did not show any effect on bronchial inflammation on biopsy [38] or airway cellular inflammation [42]. Macgregor et al showed that weight loss in obese asthmatics was associated with a $48 \%-100 \%$ remission of asthma symptoms and use of asthma medication $[43,44]$. Dixon et al found two groups of obese asthmatics, one with early onset disease and high IgE that did not improve with surgery, and a second group with low IgE that improved with surgery [14]. Furthermore, it has been previously shown that inhaled corticosteroids treatment causes similar improvements in $\mathrm{FEV}_{1}$ in obese than non-obese asthmatics, despite having considerably less effect on symptoms in the obese [10]. Nowadays, the current general GINA guidelines are used in obese patients but we should be aware that asthma control questionnaires may not reflect the reality of asthma control but may be influenced by obesity-related symptoms. Weight loss does not improve airway eosinophilic inflammation. It is therefore probable that weight loss induced improvements in asthma control defined as symptoms, lung function and use of medication due to a reduction in mass load on the respiratory symptoms rather than improvements in asthma per se. In adults it appears that weight loss of at least $10 \%$ is required to produce a significant improvement in asthma control [45]. De-conditioning from lack of exercise could also play a role in the relationship between obesity and the clinical expression of asthma [46]. It has been previously shown that exercise can reduce allergic airway inflammation through effects on regulatory T-cell function in a murine asthma model
[47]. The approach of obese asthmatics should combine pharmacologic and non-pharmacologic therapies, including exercise, weight loss and dietary interventions and the stepping up ICS therapy should be reserved to eosinophilic phenotype. Moreover future studies must investigate how diet changes and microbiome can affect outcomes in obese asthmatics [48].

Weight reduction is likely to be at least as important as pharmacological therapy in obese adults with asthma symptoms. Whether macrolides, targeting neutrophilic inflammation could be a therapeutic option in obese asthmatics has not yet been investigated.

It has been argued that late onset non allergic obese asthma (LONA) and early onset allergic obese asthma (EOA) were characterized by different pathophysiology and response to treatment. EOA is more a type- 2 disease while LONA is driven by a non type- 2 inflammation. We did not find age of onset as a predictor of response to ICS treatment.

Most of the published studies on obese asthmatics have however relied on self-reporting of physician diagnosis of asthma and recall questionnaires for respiratory symptoms and medications which lead to a clear risk of misdiagnosis. In this study, asthmatics were diagnosed based on proof of airway variability or airway responsiveness to methacholine challenge. We did not exclude current smokers in our reallife study. Smoking may induce non type- 2 inflammation and worsen asthma symptoms. Cigarette exposure is responsible for neutrophilic inflammation and neutrophils apoptosis leading to damage-associated molecular pattern (DAMPs), which may amplify smoking induced airway inflammation by promoting epithelial pro-inflammatory response [49]. The proportion of smokers was however similar in obese and normal-weight patients so we can suspect that smoking itself does not explain the difference seen between obese and normal weight patients in terms of asthma control. Moreover a sub analysis after exclusion of current smokers confirmed the same predictors of response to inhaled corticosteroids. Smoking cessation however remain of upmost importance in the management of asthmatics.

Our results suggest that respiratory physicians should measure inflammation, especially in these obese patients, to avoid unnecessary step-up in ICS dose related to persistent symptoms of dyspnea. In the presence of a "type-2" pattern, ICS will improve asthma symptoms while in the presence of neutrophilic inflammation or a restriction profile, weight loss may improve asthma outcomes and treatment should involve bronchodilators and low to moderate doses of ICS. Obesity is a well-known comorbidity in asthma and should be targeted in addition to the treatment of cortico-sensitive inflammation. Future research should aim to find novel biomarkers that might help identify these sub-phenotypes [50].

In our unselected population of asthmatic, we found that markers of bronchial eosinophilic inflammation such as FeNO [51,52] and sputum eosinophils predict a good response to ICS in obese asthmatics while a restrictive pattern and neutrophilic inflammation may identify a subgroup of patients that can deteriorate with the increase in ICS dose. In those patients, management of obesity should be the first choice. Increasing corticosteroid doses based on poor asthma control, as currently recommended in current guidelines, may thus lead to ICS overtreatment in non-eosinophilic obese asthma. Much attention should be paid to eosinophilic markers in this particular population of asthmatics.

\section{CRediT authorship contribution statement}

S. Peerboom: Conceptualization, Methodology, Data curation. S. Graff: Methodology, Data curation. L. Seidel: Formal analysis, Data curation. V. Paulus: Data curation. M. Henket: Data curation. C. Sanchez: Data curation. F. Guissard: Data curation. C. Moermans: Data curation. R. Louis: Conceptualization, Writing - review \& editing. F. Schleich: Conceptualization, Data curation, Formal analysis, Methodology, Supervision, Writing - original draft, Writing - review \& editing. 


\section{Acknowledgements}

We thank the Federal governement for the Belgian grant - EOS project 30565447.

\section{References}

[1] F. Schleich, G. Brusselle, R. Louis, O. Vandenplas, A. Michils, C. Pilette, et al., Heterogeneity of phenotypes in severe asthmatics. The Belgian Severe Asthma Registry (BSAR), Respir. Med. (2014).

[2] D.A. Beuther, E.R. Sutherland, Overweight, obesity, and incident asthma: a metaanalysis of prospective epidemiologic studies, Am. J. Respir. Crit. Care Med. (2007).

[3] B. Taylor, D. Mannino, C. Brown, D. Crocker, N. Twum-Baah, F. Holguin, Body mass index and asthma severity in the National Asthma Survey, Thorax (2008).

[4] C.A. Camargo, S.T. Weiss, S. Zhang, W.C. Willett, F.E. Speizer, Prospective study of body mass index, weight change, and risk of adult- onset asthma in women, Arch. Intern. Med. (1999).

[5] S.T. Weiss, S. Shore, Obesity and asthma: Directions for research, Am. J. Respir. Crit. Care Med. (2004).

[6] S.W. Littleton, Impact of obesity on respiratory function, Respirology (2012).

[7] T.S. Hallstrand, M.E. Fischer, M.M. Wurfel, N. Afari, D. Buchwald, J. Goldberg, Genetic pleiotropy between asthma and obesity in a community-based sample of twins, J. Allergy Clin. Immunol. (2005).

[8] Z. Ali, C.S. Ulrik, Obesity and asthma: A coincidence or a causal relationship? A systematic review, Respir. Med. (2013).

[9] Global Initiative for Asthma. Global Strategy for Asthma Management and Prevention, 2018. Available from: www.ginaasthma.org [Internet]. 2018. Available from: http://www.ginaasthma.org.

[10] M. Peters-Golden, A. Swern, S.S. Bird, C.M. Hustad, E. Grant, J.M. Edelman, Influence of body mass index on the response to asthma controller agents, Eur. Respir. J. (2006).

[11] L.P. Boulet, E. Franssen, Influence of obesity on response to fluticasone with or without salmeterol in moderate asthma, Respir. Med. (2007).

[12] R.L. Jones, M.M.U. Nzekwu, The effects of body mass index on lung volumes, Chest (2006).

[13] D.G. Chapman, C.G. Irvin, D.A. Kaminsky, P.M. Forgione, J.H.T. Bates, A.E. Dixon, Influence of distinct asthma phenotypes on lung function following weight loss in the obese, Respirology (2014).

[14] A.E. Dixon, R.E. Pratley, P.M. Forgione, D.A. Kaminsky, L.A. Whittaker-Leclair, L.A. Griffes, et al., Effects of obesity and bariatric surgery on airway hyperresponsiveness, asthma control, and inflammation, J. Allergy Clin. Immunol. (2011).

[15] W.C. Moore, D.A. Meyers, S.E. Wenzel, W.G. Teague, H. Li, X. Li, et al., Identification of asthma phenotypes using cluster analysis in the Severe Asthma Research Program 10, Am. J. Respir Crit. Care Med. 181 (2010) 315-323 (15354970 (Electronic)).

[16] E.R. Sutherland, E. Goleva, T.S. King, E. Lehman, A.D. Stevens, L.P. Jackson, et al., Cluster analysis of obesity and asthma phenotypes, PLoS One (2012).

[17] R. Louis, J. Sele, M. Henket, D. Cataldo, J. Bettiol, L. Seiden, et al., Sputum eosinophil count in a large population of patients with mild to moderate steroid-naive asthma: distribution and relationship with methacholine bronchial hyperresponsiveness 2, Allergy (2002) 907-912 (0105-4538 (Print)).

[18] E.F. Juniper, G.H. Guyatt, R.S. Epstein, P.J. Ferrie, R. Jaeschke, T.K. Hiller, Evaluation of impairment of health related quality of life in asthma: development of a questionnaire for use in clinical trials 1, Thorax (1992) 76-83 (0040-6376 (Print)).

[19] Juniper EF, O'Byrne PM, Guyatt GH, Ferrie PJ, King DR. Development and validation of a questionnaire to measure asthma control 2. EurRespirJ. 1999 Oct;14(0903-1936 (Print)):902-7.

[20] Delvaux M, Henket M, Lau L, Kange P, Bartsch P, Djukanovic R, et al. Nebulised salbutamol administered during sputum induction improves bronchoprotection in patients with asthma 1. Thorax. 2004 Feb;59(0040-6376 (Print)):111-5.

[21] E.S. Ford, D.M. Mannino, S.C. Redd, A.H. Mokdad, D.A. Galuska, M.K. Serdula, Weight-loss practices and asthma: Findings from the behavioral risk factor surveillance system, Obes. Res. (2003).

[22] W.J. Anderson, B.J. Lipworth, Does body mass index influence responsiveness to inhaled corticosteroids in persistent asthma? Ann Allergy, Asthma Immunol, 2012.

[23] F. Holguin, E.R. Bleecker, W.W. Busse, W.J. Calhoun, M. Castro, S.C. Erzurum, et al., Obesity and asthma: An association modified by age of asthma onset, J. Allergy Clin. Immunol. (2011).

[24] N. Behazin, S.B. Jones, R.I. Cohen, S.H. Loring, Respiratory restriction and elevated pleural and esophageal pressures in morbid obesity, J. Appl. Physiol. (2010).

[25] S. Rutting, S. Mahadev, K.O. Tonga, D.L. Bailey, J.R. Dame Carroll, C.E. Farrow, et al., Obesity alters the topographical distribution of ventilation and the regional response to bronchoconstriction, J. Appl. Physiol. (2020).

[26] Pavord ID, Brightling CE, Woltmann G, Wardlaw AJ. Non-eosinophilic corticosteroid unresponsive asthma. Lancet. 1999 Jun 26;353(0140-6736 (Print)):2213-4.

[27] S. Demarche, F. Schleich, M. Henket, V. Paulus, R. Louis, T. Van Hees, Step-down of inhaled corticosteroids in non-eosinophilic asthma: A prospective trial in real life, Clin. Exp. Allergy (2018;48(5).).

[28] S.F. Demarche, F.N. Schleich, M.A. Henket, V.A. Paulus, T.J. Van Hees, R.E. Louis, Effectiveness of inhaled corticosteroids in real life on clinical outcomes, sputum cells and systemic inflammation in asthmatics: A retrospective cohort study in a secondary care centre, BMJ Open. (2017).

[29] H.A. Scott, L.G. Wood, P.G. Gibson, Role of Obesity in Asthma: Mechanisms and Management Strategies, Current Allergy and Asthma Reports (2017).

[30] N. Esser, S. Legrand-Poels, J. Piette, A.J. Scheen, N. Paquot, Inflammation as a link between obesity, metabolic syndrome and type 2 diabetes, Diabetes Res. Clin. Pract. (2014).

[31] C.E. Juge-Aubry, E. Henrichot, C.A. Meier, Adipose tissue: A regulator of inflammation, Clinical Endocrinology and Metabolism, Best Practice and Research, 2005.

[32] E.D. Telenga, S.W. Tideman, H.A.M. Kerstjens, N.H.T.T. Hacken, W. Timens, D.S. Postma, et al., Obesity in asthma: More neutrophilic inflammation as a possible explanation for a reduced treatment response. Allergy Eur, J. Allergy Clin. Immunol. (2012).

[33] H.A. Scott, P.G. Gibson, M.L. Garg, L.G. Wood, Airway inflammation is augmented by obesity and fatty acids in asthma, Eur. Respir. J. (2011).

[34] S. Komakula, S. Khatri, J. Mermis, S. Savill, S. Haque, M. Rojas, et al., Body mass index is associated with reduced exhaled nitric oxide and higher exhaled 8-isoprostanes in asthmatics, Respir. Res. (2007).

[35] H.A. Periyalil, L.G. Wood, H.A. Scott, M.E. Jensen, P.G. Gibson, Macrophage activation, age and sex effects of immunometabolism in obese asthma, Eur. Respir. J. (2015).

[36] T.J.T. Sutherland, J.O. Cowan, S. Young, A. Goulding, A.M. Grant, A. Williamson, et al., The association between obesity and asthma: Interactions between systemic and airway inflammation, Am. J. Respir. Crit. Care Med. (2008).

[37] D.C. Todd, S. Armstrong, L. D'Silva, C.J. Allen, F.E. Hargreave, K. Parameswaran, Effect of obesity on airway inflammation: A cross-sectional analysis of body mass index and sputum cell counts, Clin. Exp. Allergy (2007).

[38] A. Van Huisstede, A. Rudolphus, M.C. Cabezas, L.U. Biter, G.J. Van De Geijn, C. Taube, et al., Effect of bariatric surgery on asthma control, lung function and bronchial and systemic inflammation in morbidly obese subjects with asthma, Thorax (2015).

[39] C.R. McLachlan, R. Poulton, G. Car, J. Cowan, S. Filsell, J.M. Greene, et al., Adiposity, asthma, and airway inflammation, J. Allergy Clin. Immunol. (2007).

[40] S. Demarche, F. Schleich, M. Henket, V. Paulus, T. Van Hees, R. Louis, Detailed analysis of sputum and systemic inflammation in asthma phenotypes: Are paucigranulocytic asthmatics really non-inflammatory? BMC Pulm Med (2016).

[41] B. Stenius-Aarniala, T. Poussa, J. Kvarnström, E.L. Grönlund, M. Ylikahri, P. Mustajoki, Immediate and long term effects of weight reduction in obese people with asthma: Randomised controlled study, Br. Med. J. (2000).

[42] Proceedings of the American Thoracic Society 7 (5) (2010) 325-335, https://doi. org/10.1513/pats.200903-013ST.

[43] A.M.C. Macgregor, R.A. Greenberg, Effect of Surgically Induced Weight Loss on Asthma in the Morbidly Obese, Obes Surg Incl Laparosc Allied Care. (1993).

[44] M.M. Murr, M.R. Siadati, M.G. Sarr, Results of Bariatric Surgery for Morbid Obesity in Patients Older than 50 Years, Obes Surg Incl Laparosc Allied Care. (1995).

[45] J. Ma, P. Strub, L. Xiao, P.W. Lavori, C.A. Camargo, S.R. Wilson, et al., Behavioral weight loss and physical activity intervention in obese adults with asthma: A randomized trial, Ann Am Thorac Soc. (2015).

[46] D.D. Sin, R.L. Jones, S.F. Paul Man, Obesity is a risk factor for dyspnea but not for airflow obstruction, Arch. Intern. Med. (2002).

[47] T. Lowder, K. Dugger, J. Deshane, K. Estell, L.M. Schwiebert, Repeated bouts of aerobic exercise enhance regulatory $\mathrm{T}$ cell responses in a murine asthma model, Brain Behav. Immun. (2010).

[48] M. Fricker, P.G. Gibson, H. Powell, J.L. Simpson, I.A. Yang, J.W. Upham, et al., A sputum 6-gene signature predicts future exacerbations of poorly controlled asthma, J. Allergy Clin. Immunol. (2019).

[49] I.H. Heijink, S.D. Pouwels, C. Leijendekker, H.G. De Bruin, G.J. Zijlstra, H. Van Der Vaart, et al., Cigarette smoke-induced damage-associated molecular pattern release from necrotic neutrophils triggers proinflammatory mediator release, Am. J. Respir. Cell Mol. Biol. (2015).

[50] F.N. Schleich, D. Zanella, P.-H. Stefanuto, K. Bessonov, A. Smolinska, J.W. Dallinga, et al., Exhaled Volatile Organic Compounds Are Able to Discriminate between Neutrophilic and Eosinophilic Asthma, Am. J. Respir. Crit. Care Med. (2019).

[51] F.N. Schleich, L. Seidel, J. Sele, M. Manise, V. Quaedvlieg, A. Michils, et al., Exhaled nitric oxide thresholds associated with a sputum eosinophil count $\geq 3 \%$ in a cohort of unselected patients with asthma, Thorax (2010).

[52] F.N. Schleich, M. Manise, J. Sele, M. Henket, L. Seidel, R. Louis, Distribution of sputum cellular phenotype in a large asthma cohort: Predicting factors for eosinophilic vs neutrophilic inflammation, BMC Pulm Med (2013). 